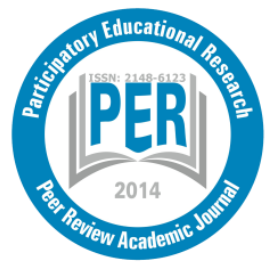

Participatory Educational Research (PER)

Vol.9(1), pp. 362-387, January 2022

Available online at http://www.perjournal.com

ISSN: 2148-6123

http://dx.doi.org/10.17275/per.22.20.9.1

\title{
Developing a guiding model of educational leadership in higher education during the COVID-19 pandemic: A grounded theory study
}

\author{
Gürol Yokuș* \\ Department of Educational Sciences, Sinop University, Sinop, Turkey \\ ORCID: 0000-0002-4849-5829
}

Article history

Received:

13.10.2020

Received in revised form:

18.07.2021

Accepted:

15.08.2021

Key words:

Leadership for the new normal, Social network analysis,

Educational leadership in times of pandemic,

Grounded theory of educational leadership

This research aims to explore educational leadership during the COVID-

19 pandemic from the perspectives of higher education students and to develop a guiding model of educational leadership for 'new normal' with the novel emerging components. This research is conducted using grounded theory method and social network analysis. The first study group includes 32 participants, second study group includes another 26 participants, and final group includes 12 participants. Participants in all groups are university students studying in a higher education institution in Turkey. Written documents, personal interviews and group discussion are used for data collection. Based on analysis, a guiding model is developed which illustrates the concept of educational leadership for the new normal, which is composed of "networking, enhancing educational practices, calmness \& compassion, analytical \& strategical thinking, and transparency". Also, the social network analysis shows that "encouraging online communities, promoting social interaction, creating a safe and inclusive learning environment, providing learning resources, leading under pressure, emphasizing optimism, making data-driven decisions" are cornerstones in terms of educational leadership for the new normal. In addition to those substantially noted key concepts, some higher education students also seem to be in need of some other aspects of educational leadership such as inspiration for learning, open dialogue, risk planning and leveraging capacity of community. The participants also indicate that successful educational leadership is about understanding others' perspectives, rather than sticking to leader's perspective.

\section{Introduction}

In the $21^{\text {st }}$ century, the world has witnessed the COVID-19 pandemic which forces humans of all colours and ages to a new style of living which is called as the new normal (Akbari \& Pratomo, 2021; Fleming \& Millar, 2019; Francisco \& Nuqui, 2020; Strack, Kugel, Dyrchs \& Tauber, 2020) and this new normal reflects unfamiliar changes not only in social life, economy, health but also in educational institutions (de Moura, 2020; Murashkin \& Tyrväinen, 2020). It has become so clear that leadership is one of the crucial concepts in this pandemic in educational institutions of most communities across the world. As implied by Harper (2020), COVID-19 is affecting higher education institutions in terms of most aspects

\footnotetext{
* Correspondency: gyokus@ sinop.edu.tr
} 
such as teaching, learning and employment. As educators, there is a need for a full understanding of what has changed in students' perceptions of educational leadership during COVID-19 crisis and creating necessary educational policies for addressing students' needs in this globally alarming threat. As thinking on new normal in education, the digitalization has been a bridge of hope for millions of students from primary school to higher education, and especially traditional roles of educational leaders have changed during this new unfamiliar situation. Social distance principle and students' making use of digital and virtual platforms lead to a change in educational leaders' role of leading, inspiring and transforming (Unesco, 2020). This change is also felt in higher education (Harris, 2020; Marshall, Roache \& MoodyMarchall, 2020; Varela \& Fedynich, 2020). Educational leaders should be adapted to this new normal with starting from understanding higher education learner's leadership perceptions. Educational leadership is becoming increasingly complex as the society becomes more at the local, state, and federal levels (Vogel, 2012). The role of educational leaders is of considerable importance in higher education for many reasons, as explained by Amey (2006) that educational leaders create learning environments with cultural awareness, serve as collaborators in developing knowledge and engagement, serve as facilitators who promote collaboration, collective responsibility, an interest in common good; and serve as leaders via partnerships in web-like and non-hierarchical systems.

When we have a look at literature, it is easily noticed that leadership has been a research topic in business area; however, there are insufficient but growing number of studies which examine leadership practices in higher education and leadership in the educational institutions, these studies especially review the new styles of leadership such as transformational leadership (Harris, Moran \& Moran, 2004; Jameel \& Ahmad 2019). This study stresses the need for an adaptable educational leadership when educators have to adapt to the changing risky situations just like the COVID-19 pandemic. This study also attempts to explore leadership from transformative and socially responsible perspectives because educational leadership in higher education is supposed to include instructional, affective, and social dimension both in formal and non-formal settings.

By its nature, leadership is situational and contextual (Antonakis \& Schyns 2012). Therefore, it gets complicated to explain leadership with one prescribed definition; but the current literature on leadership in higher education gives us considerable insights (Middlehurst, Goreham \& Woodfield, 2009). To note, when it comes to level of higher education, there is a growing interest in defining what leadership means. For instance, Juntrasook (2014) identifies four overarching means of leadership in higher education: 'leadership as position', 'leadership as performance', 'leadership as practice' and 'leadership as professional role model'. Leadership as position means taking on a formal role in a headship position. Leadership as performance means demonstrating competency and accomplishment in professional contexts. Leadership as practice means interactions or activities that involve colleagues, students, and team members, who are often positioned as followers. Leadership as professional role means acting as always already leaders by virtue of their profession. Related to higher education, especially distributed leadership (it offers more clarity as explained by Bolden, Petrov and Gosling, 2009), collective leadership, transformational leadership, socially responsible leadership are proposed in literature for higher education (Bolden et al. 2009; Dugan, \& Komives, 2010; Harvey et al. 2003; Middlehurst et al. 2009) which are more democratic models of leadership. Distributed leadership is the most influential leadership model according to Bolden et al. (2009) as it allows shared, collective leadership practices and as it has a "rhetorical value in terms of identity, participation, influence and also can equally cover the underlying dynamics of power within universities". Another influential leadership theory 
proposed in literature is transformational leadership as this leadership theory is concerned with "the charisma, intellectual stimulation and consideration of individual leaders" (Bass, 1985; Spendlove, 2007). Socially responsible leadership is also prominent in higher education which is based on Social Change Model and it is frequently used in the leadership development programs by universities (Dugan \& Komives, 2007; Komives, Owen, Longerbeam, Mainella \& Osteen, 2005; Külekçi, 2015; Yokuş, 2018). This COVID-19 pandemic clearly shows the need for a leadership model in higher education which emphasizes social responsibility such as self-knowledge, cooperation, common purpose, and change in today's globalizing society.

This study is concerned with higher education students' expectations from educational leadership during COVID-19 crisis. Education has taken a different form during pandemic, and it occurs to a very large extent in non-formal settings via online or offline meetings in virtual environments. Balwant (2016) in his study on educational leadership in higher education emphasizes that in higher education context, educational leaders influence students both in class interactions and also in other course-related to interactions in non-formal settings like offline meetings and informal discussions, which is a clear indicative characteristic of pandemic crisis. It is therefore evident that the role of strong educational leadership in terms of school/university improvement is non-negligible, and it influences even curriculum development. It becomes a necessity in this pandemic crisis to identify the interaction and patterns of influence between students (followers) and educational leaders in higher education. Educational leadership for a decade has become more prevalent and popular term replacing the terms of school leadership, school management or educational administration (Gunter, 2004). Educational leaders in higher education basically include leaders such as instructors, principals, superintendents, faculty deans, directors, head of programs, department chairs, academic advisers, curators, vice-chancellor, and rector. Educational leadership is defined by James, Connolly and Hawkins (2019) as "legitimate interaction in an educational institution intended to enhance engagement with the institutional primary task". In other definitions, the emphasis in mostly on the influence to achieve organizational goals (Bush \& Glover 2014; Greenfield, 1995). James et al. (2019) distinguish three elements of educational leadership which involve images (facts, ends, goals,), instruments (face-to-face or online communication tools) and interactions (one way or two-way). In study of Sellami, Sawalhi, Romanowski and Amatullah (2019) on educational leadership, they argue that educational leadership is unfortunately considered to be confined exclusively to educational settings. However, it would be a better understanding of educational leadership when it is posited 'anywhere' and 'everywhere', rather than limiting it to educational setting. They suggest in their study to regard educational leaders responsible for building learning organizations, not just hold them responsible for schools. This is a very appropriate suggestion relevant for educational leaders of 21st-century educational institutions as there is a challenging task for them to rethink strategically the institutional primary goals and also prepare students for learning for future. As asserted by Brooks and Normore (2009), it is felt the need to rethink the practices of educational leadership for contemporary world. Regarding the improvement of educational leaders' practices and qualifying their pedagogy, they put stress on "glocalization" which incorporates the successful integration of local and global forces. They explore nine dynamic and interconnected knowledge domains of literacy to be developed by educational leaders of 21 st-century which are listed as political literacy, economic literacy, cultural literacy, moral literacy, pedagogical literacy, information literacy, organizational literacy, spiritual and religious literacy, and temporal literacy. To view current leadership practices as a temporary solution until normal service misses the opportunity to lead differently and potentially, to lead more effectively (Harris, 2020). As seen in most of these 
studies about leadership literature, researchers attempt to explore how educational leaders' practices influence students' state of mind, achievement, satisfaction, or other situations associated with school improvement.

When studies about leadership during COVID-19 crisis, there are conducted a number of studies which focus on leadership during pandemic (Akbari \& Pratomo, 2021; ChisholmBurns, Brandon \& Spivey, 2021; de Moura, 2020; Dumulescu \& Mutiu, 2021; Fernandez \& Shaw, 2020; Fleming \& Millar, 2019; Francisco \& Nuqui, 2020; Murashkin \& Tyrväinen, 2020; Strack et al., 2021). During the lockdown period, strategic planning in higher education focused on mostly preparation for online instruction and assessment (Loriggio, 2020). Learners in higher education systems are caught up in online webinars, instructional videos, live learning experiences and- resources for teachers, parents, and students (Osmond-Johnson, Campbell \& Pollock 2020). Training sessions have been organized for students and faculty staff to prepare them to navigate this new virtual modality of teaching. These challenges call for a critical view of educational leadership in times of crisis. This view is supported by Gurr and Drysdale (2020) who emphasize that leadership is about setting direction and often it requires the courage to take strategic risks. Roache, Rowe-Holder, and Muschette (2020) propose that skilled leadership is necessary during COVID-19 for implementing effective policies aligned with university's mission and vision, providing professional development and training for learners in new virtual modality of learning.

In study of Lawton-Misra and Pretorius (2021), they draw attention to not only the critical role leaders must play in taking responsibility for their organizations and people, but also the complexity of that leadership role. It comes out that the leadership qualities needed during COVID-19 crisis appear as empathy, vulnerability, self-awareness, and agility. There are necessary for decreasing affective intensity experienced by faculty staff and students (Lawton-Misra \& Pretorius, 2021) who are facing emotional distress as a direct result of the pandemic (Roy et al. 2020). For instance, in order to reduce the stress of staying at home for an extended period of time, some universities in China provided counseling services to students (Wang, Cheng, Yue \& McAleer, 2020). Samoilovich (2020) notes that this pandemic in higher education is a period of experimentation in every sense. During crisis, rectors and academic leaders should adopt "test and learn" attitude, adapt quickly and -beyond crisisidentify opportunities. Chisholm-Burns, Brandon and Spivey (2021) stress out the unknown impacts of pandemic especially in higher education. They analyze the perceptions of students in a college of pharmacy. They conclude that overpromising is not right, adapting to change and consistency in communication are essential for leadership during COVID-19 in higher education. Importance of communication, adaptability, flexibility and maintaining connection are stressed out by administrators, faculty, and students. This finding is supported in study of Dumulescu and Muţiu (2021) who emphasize that educational/academic leaders in higher education have to make decisions and to act quickly to manage large educational communities, addressing students', teachers', and staff's needs, as well as society's needs. They explain the certain challenges experienced by academic leaders in a university in Romania during COVID-19 pandemic. Their findings indicate some leadership insights during pandemic include leader's personal attributes, unity through decentralization, and opportunities to reinvent the university. In addition, Samoilovich (2020) draws attention that COVID-19 pandemic necessitates strengthening leadership which requires greater transparency. This pandemic makes decision-making difficult. However, in addition to governing bodies, administrative boards, academic councils, agile and multifunctional teams with clear objectives can serve for a better leadership. This crisis gives the opportunity to test forms of shared governance that integrate managers, academic leaders, and administrative 
personnel in a process of assessing the viewpoints of all engaged stakeholders when defining courses of action. To ensure the physical and mental wellbeing of students and faculty during COVID-19 pandemic, it is necessary to build trust, maintain a sense of community and common purpose (Samoilovich, 2020).

Lawton-Misra and Pretorius (2021) explain that leadership in higher education calls for unlearning and relearning certain behaviours to lead during the pandemic. To exemplify, relinquishing control, moving away from a top-down leadership style to a more distributive approach, collective leadership, adapting to the fluidity of the situation are among skills and competencies of leaders in higher education. COVID-19 pandemic demonstrates the need for individuals and groups to work concurrently and collaboratively in order to achieve leadership outcomes. It has become necessary to abandon the idea of a leader/follower dualism (Bolden, 2020; Lawton-Misra \& Pretorius, 2021). Fernandez and Shaw (2020) also support that making connections with people at all levels of the institution during pandemic crisis, allows the leader to be truly transformative and the collaboration to be meaningful. Therefore, collective leadership is more stressed. According to Maas et al. (2020), collective leadership becomes more important as this crisis has more negative effects on those whose representation and equality is still too little known (for example, ethnic and racial minorities, disabled individuals etc.). Fernandez and Shaw (2020) claim that autocratic leadership is inefficient during pandemic which come with complexities and uncertainties. In response to crisis, it may be implemented a type of distributed leadership which absolutely takes time, increases the quality of decisions considering multiple perspectives (Fernandez \& Shaw, 2020) and more efficient than other leadership approaches (Berjaoui \& Karami-Akkary, 2019). Antonopoulou et al. (2021) stress that another leadership among the different models of educational leadership is transformational leadership which is one of the most appropriate models in higher education, especially during pandemic. Transformational leadership focuses on the division of leadership among educators with different skills to collectively manage necessary leadership tasks in different contexts.

In study of Marshall, Roache and Moody-Marshall (2020), they comparatively analyze the current leadership during pandemic in Barbardos and Canada and emphasize four main leadership behaviours which are critical during COVID-19 pandemic. Educational leadership for new normal are indicated as providing clear direction, communicating effectively, working collaboratively, and engaging in adaptive leadership. Boin, Kuipers and Overdijk (2013) also draw attention to leadership-in-crisis and lists early recognition, sense-making, making critical decisions, orchestrating vertical and horizontal coordination, coupling and decoupling, meaning-making, effective communication, rendering accountability, learning, and enhancing resilience as indicators of leadership in times of crisis. Pekkola et al. (2021) investigate how Finnish universities manage COVID-19 pandemic and find out that certain limitations to effective academic leadership in higher education during pandemic include that instructions from the authorities are ambiguous, leaving much room for interpretation. Educational leaders hope for more open conversations, negotiations, and more cooperation. Educational leaders face challenges in relation to crisis management including massive increase in requests; uneven impact on workload (i.e., overloaded leaders); a lack of information on academics' performance and well-being; and the stress of overlooking important information

The key research question which motives this study is "what educational leadership behaviours are fundamental in higher education during COVID-19 pandemic". Depending on this main purpose, this research attempts to answer the following research problems: 
(1) What are the higher education students' expectations from educational leaders during COVID-19 pandemic?

(2) What characteristics compose educational leadership in higher education during COVID-19 pandemic?

(3) How to develop a guiding model for educational leadership during COVID-19 pandemic?

\section{Method}

This study is designed as grounded theory. Grounded theory design is among qualitative research methods; and with its strategy and scope it takes a considerable place in contemporary educational studies, especially in interpretive research. Bryant (2017) explains detailed overview of grounded theory and suggests starting a grounded theory study without explicit hypotheses, exploring a new problem, or refining further explorations of an existing problem. According to him, tentative generalizations or theoretical assumptions can be constructed only when the discovered knowledge reaches a "saturation point". Bryman and Bell (2007) support this view by putting forward that grounded theory is dependent on coding which includes the constant comparison \& theoretical sampling, and theoretical saturation. To consider all, this study attempts to discover a theoretical model of educational leadership for new normal in higher education. This model is developed from data acquired through collected written documents, personal interviews, and group discussion. This study follows theoretical process of grounded theory designed by Izvercian, Potra and Ivascu (2016) which is illustrated in Figure 1:

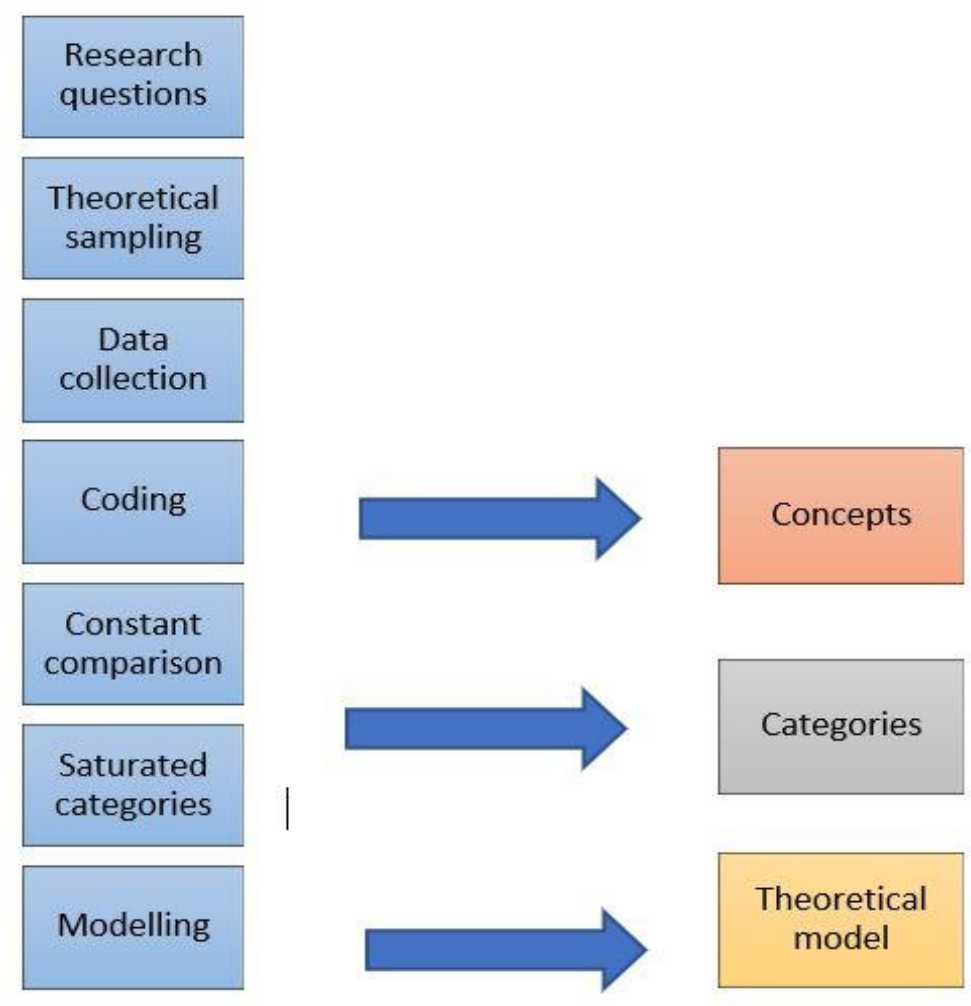

Figure 1. Theoretical process of grounded theory 


\section{Study Group}

As grounded theory study mainly aims to make generalizations and build a theory, if possible, this study includes more than one study group. Participants in all groups are university students studying in different departments in a higher education institution. In the first study group, a total of 32 participants are selected who can guide the direction of study and substantially affected from coronavirus pandemic. All selected participants have been in their hometown since COVID-19 crisis, taken online courses as a part of remote learning, struggling with their limited skills against this global crisis and deeply in need of a leadership in this process. For the theoretical sampling stage, a representative heterogeneous sample of participants have been selected and demographic qualities of all study groups are presented in Table 1.

Table.1 Demographic Qualities of All Study Groups

\begin{tabular}{|c|c|c|c|c|c|}
\hline & $\mathrm{N}$ & Age & Gender & $\begin{array}{l}\text { School } \\
\text { Experience }\end{array}$ & Department \\
\hline $\begin{array}{l}\text { First } \\
\text { Study } \\
\text { Group }\end{array}$ & 32 & $\begin{array}{l}19(n=9) \\
20(n=10) \\
21(n=10) \\
22(n=2) \\
23(n=1)\end{array}$ & $\begin{array}{l}\text { Male }(n=14) \\
\text { Female }(n=18)\end{array}$ & $\begin{array}{l}1 \text { year }(n=4) \\
2 \text { year }(n=5) \\
3 \text { year }(n=10) \\
4 \text { year }(n=13)\end{array}$ & $\begin{array}{l}\text { Education Faculty }(n=9) \\
\text { Literature }(n=3) \\
\text { Finance }(n=4) \\
\text { Fine arts }(n=5) \\
\text { Tourism }(n=6) \\
\text { Sports Academy }(n=5)\end{array}$ \\
\hline $\begin{array}{l}\text { Second } \\
\text { Study } \\
\text { Group }\end{array}$ & 26 & $\begin{array}{l}19(\mathrm{n}=8) \\
20(\mathrm{n}=12) \\
21(\mathrm{n}=3) \\
22(\mathrm{n}=3)\end{array}$ & $\begin{array}{l}\text { Male }(n=12) \\
\text { Female }(n=14)\end{array}$ & $\begin{array}{l}1 \text { year }(n=7) \\
2 \text { year }(n=7) \\
3 \text { year }(n=6) \\
4 \text { year }(n=6)\end{array}$ & $\begin{array}{l}\text { Education Faculty }(\mathrm{n}=5) \\
\text { Literature }(\mathrm{n}=3) \\
\text { Finance }(\mathrm{n}=3) \\
\text { Fine arts }(\mathrm{n}=5) \\
\text { Tourism }(\mathrm{n}=5) \\
\text { Sports Academy }(\mathrm{n}=5)\end{array}$ \\
\hline $\begin{array}{l}\text { Third } \\
\text { Study } \\
\text { Group }\end{array}$ & 12 & $\begin{array}{l}19(n=3) \\
20(n=3) \\
21(n=3) \\
22(n=3)\end{array}$ & $\begin{array}{l}\text { Male }(n=6) \\
\text { Female }(n=6)\end{array}$ & $\begin{array}{l}1 \text { year }(n=3) \\
2 \text { year }(n=3) \\
3 \text { year }(n=3) \\
4 \text { year }(n=3)\end{array}$ & $\begin{array}{l}\text { Education Faculty }(n=2) \\
\text { Literature }(n=2) \\
\text { Finance }(n=2) \\
\text { Fine arts }(n=2) \\
\text { Tourism }(n=2) \\
\text { Sports Academy }(n=2)\end{array}$ \\
\hline
\end{tabular}

First study group participants' ages range from 19 to 23 , both male $(n=14)$ and female $(n=18)$, with 1 to 4 years of school experience in their field of expertise. In order to understand diverse perspectives, university students from different discipline areas have been included such as teacher training, linguistic and literature, finance, fine arts, tourism and sports academy. In second study group, 26 new university students with ages ranging from 19 to 22 , both male $(n=12)$ and female $(n=14)$ have been included in data collection in order to catch all possible views which approach differently to the educational leadership for new normal. The third study group includes 12 participants who have been selected purposefully from those who took place in this second study group, from six faculties including males $(n=6)$ and females $(n=6)$. These participants are those who have a clear and explanatory understanding of educational leadership for new normal, believe in capacity for educational leaders in times of crisis and ambiguous future, and have ideas about successful leadership for new normal.

\section{Data Collection Process}

A survey form with open-ended questions have been used as the first data collection tool with the first study group. The items have been checked by three field experts who study 
in area of leadership and some questions have been revised according to their suggestions. The final form includes six open-ended questions in assessment tool exploring students' perspectives on educational leadership in higher education during the crisis of COVID-19. The findings obtained from this data collection tool determined the questions in the individual interviews at the next stage. Second study group is included in study and they have been interviewed individually in an online platform with a semi-structured form which has mainly seven questions and alternative backup questions and it took eight weeks at total. In terms of duration, each individual interview has lasted thirty minutes on average. This semi-structured form has been created depending on the data of first group participants. This semi-structured form has been reviewed by three faculty members working in Educational Administration Department. The revised version of form has been applied to second study group in online platform. The data has been recorded and the researcher has been taking notes in these online interviews and making his own interpretations/observations. In order to elaborate on the educational leadership for new normal, a more exclusive and rigor participants have been included. As the third study group, 12 participants included in this second group are selected purposefully who have clear and comprehensible considerations about educational leadership for new normal. They are included in two focus group-discussion in online platform until saturation of categories is reached. Saturation of the categories which is very crucial in grounded theory studies has been succeeded after interviews which took approximately 29 hours of duration. There has been made transcriptions of interviews and then analysis process. Two samples were given to the questions used in each data collection tool.

$1^{\text {st }}$ data collection tool:

- Could you tell your story about what changes happened in your school life after the pandemic?

- What do you think about the word "educational leadership" before and after the pandemic, what comes to your mind?

$2^{\text {nd }}$ data collection tool:

- Could you tell me about any educational leader you have contacted during the pandemic?

- Could you describe the characteristics of a good educational leader for the new normal?

$3^{\text {rd }}$ data collection tool:

- In what ways did educational leaders become a better leader during the pandemic?

- What features of educational leaders specifically motivated you to continue your schoolworks?

\section{Data Analysis}

In this grounded theory study, the data gathered from three sources (written openended survey form, transcriptions of interviews, and researcher' notes) have been conceptualized in detail. Then, there has been created some temporary labels to the repeating forms considering Strauss and Corbin's (1990) coding steps which start with open coding and continue with axial coding and end up with selective coding. Therefore, data analysis in this study starts with open coding which includes identifying categories, properties, and 
dimensions, then goes through axial coding which includes analyzing conditions, relations, strategies, and consequences, then ends up with selective coding which includes creating theoretical framework around an emerging plot. In open coding of this study, initial concepts have been grouped at an abstract level, which might give meaning to educational leadership. The initial concepts are labelled and memos are created for organizing them into categories. Grounded theory requires that data should be collected until reaching saturation. Data has been continued to be collected, until there is not uncovered any new concepts. Coding has been done by researcher and another independent reviewer who is familiar with how grounded theory works. Axial and selective coding is performed after the open coding in order to explore how interconnected categories are. Main categories and subcategories have been developed using axial coding in order to a unveil a model. Thirdly, selective coding has been done and categories have been integrated to create the theoretical framework at the first appearance. Member checks, rich details, triangulation, thick descriptions and peer review are used to ensure reliability and validity of the study.

\section{Findings}

Participants who involve in this educational leadership study mostly identify their academic advisers, course instructors, supervisors, faculty deans and head of programs as their educational leaders. In instance of educational leadership, they really look for intimate relationship founded on interpersonal connections and they long for digitalization in education. A grounded theory research demands a considerable amount of effort and time with extensive amounts of data. Clusters of initial codes within the open coding process includes a total of 18 emergent codes. In the next axial coding stage, the concepts are raised at a conceptual preliminary category level. In the axial coding stage, there comes out five main categories based on eighteen codes/concepts in open coding. Each category is described by its codes/concepts and is related to other categories. For example, "calmness and compassion" category has three codes which are interrelated to two other categories such as "networking" and "transparency". Table 2 presents both consolidated categories and codes which are related to educational leadership for new normal:

Table 2. Educational Leadership for the New Normal in Higher Education

\begin{tabular}{|c|c|c|c|}
\hline Consolidated categories & Frequency & Codes & Frequency \\
\hline \multirow{3}{*}{ Networking } & \multirow{3}{*}{154} & encouraging online communities & 57 \\
\hline & & promoting social interaction & 53 \\
\hline & & community-oriented & 44 \\
\hline \multirow{4}{*}{$\begin{array}{l}\text { Enhancing } \\
\text { practices }\end{array}$} & \multirow{4}{*}{149} & create supportive and & 50 \\
\hline & & environment & 44 \\
\hline & & provide learning resources & 28 \\
\hline & & $\begin{array}{l}\text { construct feedback for improvement } \\
\text { create a vision of academic success }\end{array}$ & 27 \\
\hline \multirow{4}{*}{ Calmness and compassion } & \multirow{4}{*}{148} & lead under pressure & 42 \\
\hline & & emphasize optimism & 41 \\
\hline & & care for learners & 32 \\
\hline & & inspire for learning & 33 \\
\hline \multirow{4}{*}{$\begin{array}{l}\text { Analytical and strategical } \\
\text { thinking }\end{array}$} & \multirow{4}{*}{128} & data-driven decisions & 41 \\
\hline & & risk-planning & 30 \\
\hline & & create strategies for long term & 29 \\
\hline & & leverage the capacity of community & 28 \\
\hline \multirow{3}{*}{ Transparency } & \multirow{3}{*}{110} & Trust & 40 \\
\hline & & organizational culture & 40 \\
\hline & & open dialog & 30 \\
\hline
\end{tabular}


This grounded theory research reveals that there exist five key themes of leadership for new normal. Looking at in detail to observe which categories are repeating more frequently in terms of educational leadership for new normal, it is observed that "networking" is the first most repeating category with its elements such as encouraging online communities, promoting social interaction and being community-oriented, which are highly related to educational leadership for new normal. Second most relevant category appears as "enhancing educational practices" with its elements such as creating supportive and inclusive learning environment, providing learning resources, creating a vision of academic success, and constructing feedback for improvement. Third relevant category is educational leaders' "calmness and compassion" with its elements such as leading under pressure, emphasizing optimism, care for learners, and inspire for learning. Fourth category is "analytical and strategical thinking" with its elements such as making data-driven decisions, risk-planning, creating strategies for long term and leveraging capacity of community. Fifth category is "transparency" with its elements such as trust, open dialog, and organizational culture.

Within the theme of networking, A12 claims what to expect from educational leadership during the pandemic:

"Well, for me, I want to be involved in a community... I felt the need for an online community and be in a network to meet up with educators, my friends, administrative, share what's going on and what's the plan for educational goals."

A7 reflects his thoughts on what has changed in coronavirus in terms of educational leadership:

"I understand how value networking and interaction is during this COVID-19 outbreak. Due to the constraints, really, being in an online community and having access to educational leaders such as instructors and faculty deans have precedence over anything."

Emphasizing on creating a vision of academic success, B14 explains:

"leaders' vision should be embraced by learners, too. So, it is the responsibility of educational leaders to create a vision among school staff and students by communicating with student teams, community and stakeholders. And then measure the progress".

A17 emphasizes the importance of providing resource for learning during COVID-19 pandemic:

"we get access to the study materials on online platforms...educational leaders should give training to learners on how to best utilize e-learning materials and benefit from remote learning."

Within the theme of calmness and compassion, A29 contributes by giving more details about her expectation:

"We need clear and specific messages from educational leaders in coronavirus period... I expect from leaders to stay calm, listen and respond with hopefulness".

Emphasizing caring for and inspiring others, B18 implies that: 
"We want from leaders to show they care about us. Students in higher education attach importance to be realized by their educational leaders, if they are cared, they feel appreciated."

Within the theme of transparency, trust and organizational culture are mostly emphasized. For example, B1 implies that:

"First, this pandemic teaches us how important trust is between learners and leaders... We feel supported and this trusting relationship helps us perform better both academically and managing the crisis."

B10 elaborates detailed thoughts on transparency by claiming:

"it is hard but educational leadership requires organization. I want to know the real story; how worse it is. A good leader should be trustable, needs to give honest information, and make learners feel valued and stick together."

Within the theme of analytical and strategical thinking, B11 expresses them as characteristics of educational leadership during pandemic:

"Continuous improvement is up to good and effective decisions... They should utilize data (from parent, learners etc.) in order to analyze strengths, weaknesses and what-to-do next."

A2 puts emphasis on risk planning:

"Educational leaders have a great responsibility. First of all, they should manage the crisis by planning the risks... a good leader reduces the negative effects of pandemic by planning what may go wrong and make alternative plans."

Additionally, some students emphasize educational leaders should not ignore learners' capacity, and move only with their own decisions, rather they should leverage the capacity of community. For instance, B12 expresses that:

"In addition, sometimes educational leaders ... ignore our talents... educational leadership for new normal should ... support talent development of all learners."

The last step, selective coding finds out relationship between codes and categories to reveal which categories and codes outstand most. In this stage, one of the important things to consider is which codes are central and which codes are periphery. For understanding relationship and network among codes, Social Network Analysis has been done using the programme of SocNetV tool. This analysis shows how many connections a code/concept has with other concepts. As explained by Wasserman and Faust (1994), a large number of disciplines makes use of social network analysis to examine the relationship among entities. This relationship might be connection or tie which even includes self-selected ties (Knaub, Henderson \& Fisher, 2018). Figure 2 manifests the results of Social Network Analysis which indicates how strong and mutual relationships exist between 18 codes: 


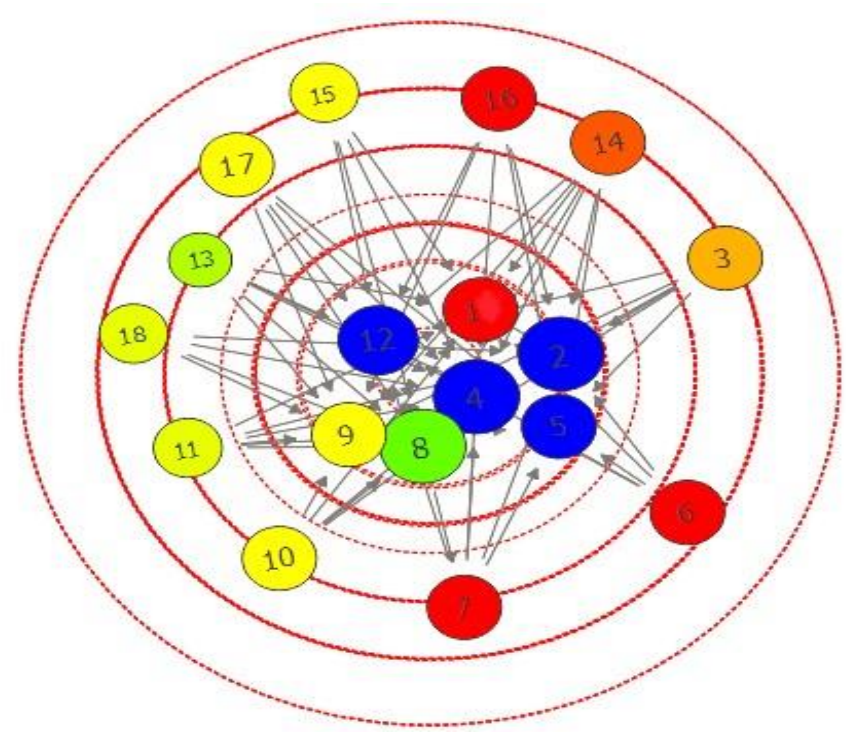

Figure 2. The relationship between 18 concepts.

Figure 2 indicates that there are 7 most outstanding codes which are in the centre of educational leadership for the new normal. When social network analysis is considered in detail, it is evident that university students put great importance to "encouraging online communities, promoting social interaction, creating a safe and inclusive learning environment, providing learning resources, leading under pressure, emphasizing optimism, making data-driven decisions" in terms of educational leadership for new normal. These codes indicate that students in times of crisis recognize the significance of being in a network which is based on social/communal merits, they value community more than personal concerns. It is possible to claim that individuality takes a new form in this pandemic process. Also, promoting optimism and social interaction are indispensable leadership traits university students expect from educational leaders. On the other hand, the analysis indicates that keeping knowledge to himself, being too self-reliant, panic, underestimating data, lack of vision are regarded as serious obstacles in terms of the educational leadership for new normal. Although there are substantially noted key concepts, some participants also need for some other aspects of educational leadership such as inspiration for learning, open dialogue, risk planning and leveraging capacity of community. The participants also indicate that a successful educational leadership is about understanding others' perspectives, rather than sticking to leader's perspective. They stress that each individual has their own vision differing from the leader; therefore, they note on the necessity of developing a vision for the whole student community and school program.

The inductive data analysis and social network analysis strictly following the axial and selective coding procedures give considerable meaning to understanding of the educational leadership. To start with, networking, enhancing educational practices, calmness and compassion are fundamental for educational leadership. These dimensions are followed by analytical \& strategical thinking and transparency. During crisis, -still not as much as socioemotional factors- the importance of analytical \& strategical thinking and transparency is nonnegligible for educational leadership in times of pandemic. There is interconnectedness rather than hierarchy among dimensions of educational leadership emerging in this grounded theory. The data analysis has also resulted in a theoretical framework of the educational leadership for new normal. There has been developed a guiding model of educational leadership for new normal, which is illustrated in Figure 3: 


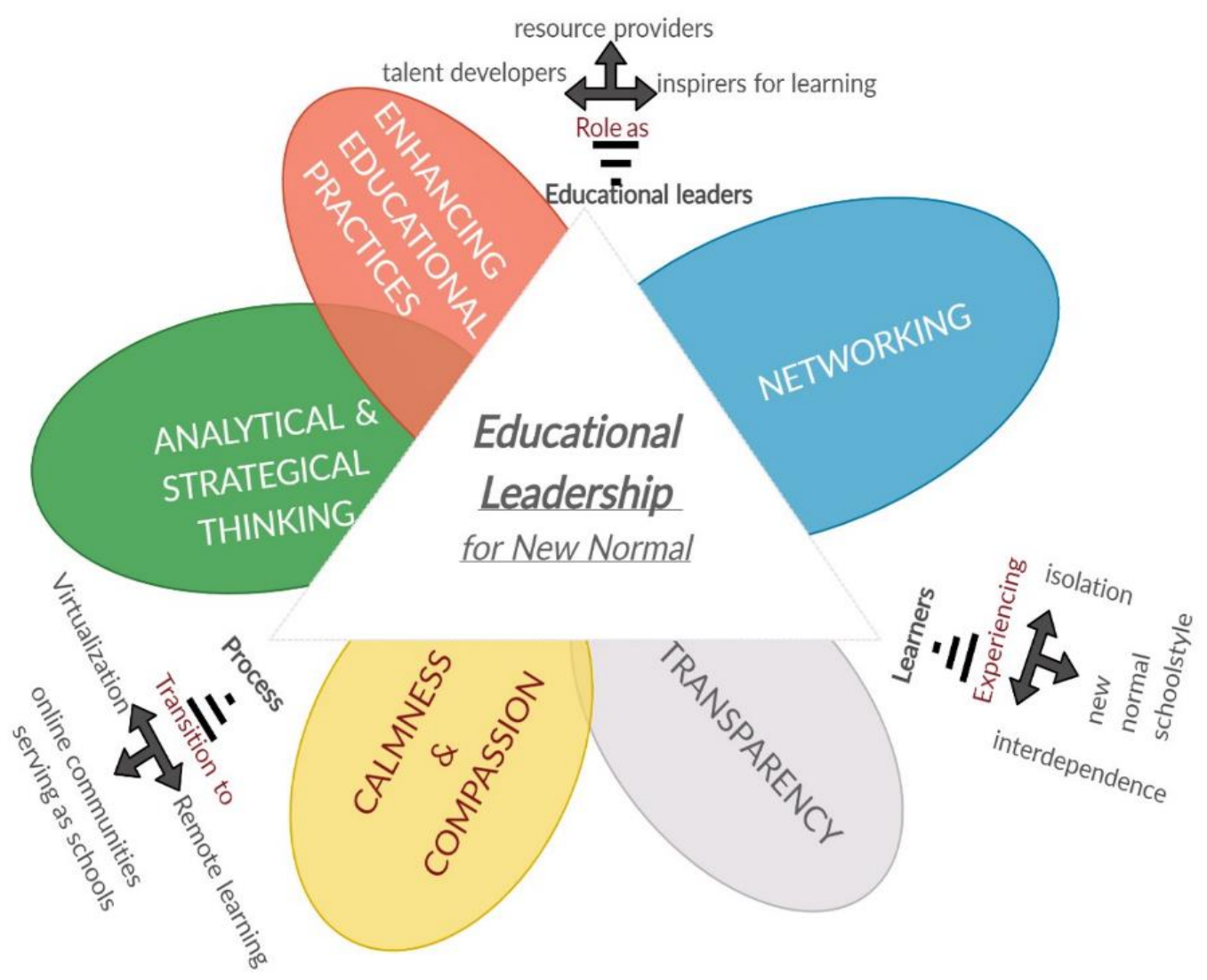

Figure 3. A guiding model of educational leadership for new normal

Figure 3 illustrates that in this educational leadership model for new normal, educational leaders serve as three major roles: resource providers, inspirers for learning and talent developers. Instruction is transforming into virtualized and remote learning, and online communities are replacing for physical schools. Learners are exceptionally experiencing isolation both physically and emotionally, and attempt to get used to new normal school style. Educational leaders for new normal should start with ensuring networking. Then they are expected to enhance educational practices within online learning communities by creating a vision, providing sources, and constructing feedback. However, it is a key point to satisfy students emotional needs which are greatly affected by educational leaders' calmness and compassion. Analytical and strategical thinking which include data-driven decisions and longterm strategies help educational leaders to build a strong leadership for the crisis. Lastly, transparency in educational leadership is important during COVID-19 pandemic as it keeps learners in an informed, open and trust mood.

\section{Discussion and Results}

This grounded theory research is focused on exploring educational leadership from perspectives of higher education students during COVID-19 pandemic; and this study also attempts to develop a guiding model with identifying the newly emerged components of leadership for new normal in education. From the data analysis, five constituents of educational leadership composed of eighteen codes have been organized according to their connections with each other. The five main components of educational leadership for new normal have been built as networking, enhancing educational practices, calmness \& 
compassion, analytical \& strategical thinking, and transparency. In the following, we will present all the main variables with their sub-elements, making discussion considering literature of leadership and citations from the in-depth interviews undertaken.

a) Networking - is considered as one of the most important characteristics of educational leadership for new normal. Networking includes building online communities, promoting social interaction and being community oriented. In pandemic, the core functions of schools have shifted, and education leaders have been pushed to the very limit (Harris, 2020). A good educational leader is first and foremost expected to achieve networking by building communities- which are inherently online due to pandemic. In this study, it is obvious that online communities are the new schools and educational leadership for new normal should succeed in gathering students around common interests and lead the community emphasizing social interaction. Forty five percent of participants put emphasis on building community and promoting social interaction as one of the indicatives of leadership for new normal. They emphasize that communities should be built online and educational leaders in COVID-19 crisis should allow "a virtual point of presence" as students cannot meet physically.

Findings suggest that educational leaders in times of new normal should develop online communities and have a supportive working team in charge of providing information related to the educational goals, the learning resources, assessment, and evaluation during pandemic. Most of the students stress that an ideal community should allow for continuous interaction and knowledge sharing. Data shows that educational leaders' first and foremost qualities should be encouraging network rather than isolation, promoting social interaction and creating a vision in benefit of the whole community. Being community-oriented promotes common good and it is part of educational leadership. In study of Fernandez and Shaw (2020), leadership for new normal calls for unpredictable adaptive behaviours. They emphasize a leadership model that underlie empowerment, involvement, and collaboration. According to them, academic leaders with emotional intelligence and emotional stability should place the interests of others above their own during pandemic. Secondly, academic leaders should distribute leadership responsibilities to a network of teams throughout the organization to improve the quality of the decisions made in crisis resolution. According to them, the best leadership practices for academic leaders managing COVID-19 are considered as connecting with people as individuals and establishing mutual trust, distributing leadership throughout the organization, and communicating clearly and often with all stakeholders (Fernandez \& Shaw, 2020).

Most of the higher education students consider being community-oriented a part of networking and therefore a part of educational leadership for new normal. Students are ready to diminish their individualistic expectations to an acceptable level for the good of common. These findings are related to the concept of Lorenzi's (2004) prosocial leadership and Maak's (2007) responsible leadership. Lorenzi defines prosocial leadership as a "positive, effective influence with constructive goals that serve the common good" and expresses that leaders should lead for common good rather than satisfying narrow, personal or even greedy interests. The findings of this grounded study indicate that educational leaders for new normal should act with common interests in a collectivist manner by channeling their own desires into the common good.

During pandemic, school leaders are focusing their considerable leadership energies on engaging others in the collaborative, shared and collective work that is both vital and urgent (Harris, 2020). Networking becomes the most important component of educational leadership 
for new normal; however, it is not only important in times of pandemic; but -not as much as in new normal- it is normally a key concept for a successful school development. This viewpoint is supported by Fernandez and Shaw (2020) who state that "academic leaders should distribute leadership responsibilities to a network of teams throughout the organization to improve the quality of the decisions made in crisis resolution". Therefore, the fluidity and uncertainty surrounding the COVID-19 virus necessitates a leadership approach that focuses on networking and teams of diverse expertise throughout higher education institution.

Irvine, Lupart, Loreman and McGhie-Richmond (2010) emphasize the importance of networking as a part of educational leadership. They advocate that developing a supportive school community is as important as raising academic achievement. As claimed by Halverson (2007), educational leaders create conditions for strong communities by initiating interaction, facilitating the development of obligations, and providing systematic feedback which indicates to what degree mutual obligations are being met. Supovitz and Christman (2005) support this view by explaining that small communities allow teachers and students to get to know each other and respond to their needs better and building a community creates a culture for sustained instructional improvement, which eventually lead to student learning. In this study, students need to have a sense of community during COVID-19 outbreak in order to stay connected and informed. Out of crisis times, each student has his/her own motivations of educational leadership, prioritizing some certain features and neglecting the others. However, the data of this study indicates that leaders for new normal should promote common good without ignoring the needs of individuals with different interests. Data shows that students are motivated by involving in an online community, acting community-oriented and testifying educational leaders' contribution to the whole group. Talu and Nazarov (2020) assert that a leader in organizational contexts in the COVID-9 pandemic must be coherent, flexible, account for his/her emotions, be involved, and listen to all the opinions of others in order to carefully manage this period of crisis. The ongoing COVID-19 pandemic will have a multilateral impact on organizations, and strategically oriented leaders will formulate goals to turn challenges into victories for themselves and their organizations (Talu \& Nazarov, 2020). Murphy (2020) express extraordinary times require extraordinary measures and education systems are now developing emergency protocols. Leading the new normal is possible with strong communities and it can be asserted that this is a period transforming schools to virtual communities.

b) Enhancing educational practices - this is regarded as an essential component of educational leadership during COVID-19 pandemic. It includes creating supportive and inclusive learning environment, providing resources for learning, constructing feedback for improvement, and creating a vision of academic success. In study of Francisco and Nuqui (2020) on new normal leadership during COVID-19, it is revealed that new normal leadership is the ability to be adaptive while staying strong with one's commitment; it is about being an effective instructional decision-maker; and it's about being a good planner, vigilant, and initiator. Educational leadership -no matter during pandemic or ordinary times - is purposeful and it aims to influence specific outcomes in accordance with a vision of school and academic success. Before pandemic, educational leadership was more about developing strategies to meet educational objectives in a limited time and restricted school setting. It was not as much related to supportive \& inclusive learning environment and constructing feedback as in pandemic process. Most of the time, it was just about academic vision of schools which were often not shared by followers/learners. Marshall, Roache and Moody-Marshall (2020) took a comparative look at educational leadership during COVID-19 crisis in higher education institutions in Barbados and Canada. They stress that a vision is needed in times of crisis. 
Stakeholders feel confidence when educational leaders have an effective plan to navigate a crisis. During the COVID-19 pandemic; students, teachers, and other stakeholders have been searching for direction. Gurr and Drysdale (2020) state that setting direction is an important leadership quality during COVID-19 crisis in which strategic risk taking is placed at the forefront. It is important to note that for leaders to set a clear direction, they must engage in sense making. This involves the ability to make sense of confusing situations (Gurr \& Drysdale 2020).

Most of the students connect educational leadership with academic purposes and expect to be academically supported by educational leaders in online platforms beyond school boundaries. After networking, it comes enhancing educational practices as the highest important value of educational leadership. In study of Varela and Fedynich (2020), educational leaders reported confidence in their preparedness to lead instruction, and to support teachers, all students, and parents during remote instruction as a result of COVID-19 pandemic related school closures. To give more detail, seventy nine percent of educational leaders agreed that they were prepared to lead high quality instruction to deliver virtually. As emphasized by Pollock (2020) related to educational leaders' leading virtual schools during the pandemic, leaders' role have pivoted to concentrating on supporting educators, students, and parents in transitioning to a different way of schooling

In this study, it is obvious that approximately half of university students put emphasis on creating supportive and inclusive learning environment and constructing feedback for improvement. However, some university students complain that they face a decline in their success and academic performance as they switch to online/remote learning due to pandemic. They emphasize a key practice for educational leadership: creating a vision of academic success, a vision which is shared by all stakeholders. It is seen that educational leadership is mostly related to the school's vision and curriculum. This aspect is emphasized in the study of Wing (2013) who confirms that educational leadership includes "creating a shared sense of purpose in the school, nurturing continuous improvement through school development planning, developing an innovative school culture and the improvement of instruction, coordinating the curriculum and monitoring learner outcomes".

Within the context of enhancing educational practices, students also expect from educational leaders that resources are successfully provided for learning. This study reveals that educational leaders during COVID-19 pandemic are not just strategy developers to meet school objectives, but also resource providers, curriculum specialists, instructional supporters, talent developers and learning facilitators. In literature is reviewed, it is apparent that the explicit responsibility of educational leaders is to contribute to school capacity, academic achievement and intellectual growth and talents of learners. In study of Harris (2020), it is revealed that coronavirus is a crisis but also an opportunity to "lead differently and potentially, to lead more effectively". This is a period of leading in a digital world and universally, education leaders at all levels in the system, attempt to influence and engage with others through a screen and practice their leadership. Educational leaders as resource providers have a key role for disadvantaged groups. COVID-19 is an opportunity for educational equity. However, in the report developed by the National Foundation for Educational Research (NFER), it is found out that a third of pupils are not interested in the lessons, forty-two percent is reluctant to hand over their assignment, and students who are in disadvantaged schools are the least likely to be involved in remote/online learning. This report shows that seven out of 10 state school children have very few online lessons less than one in a day, while almost a third of private schools have been providing four or more online lessons 
every day. Approximately all teachers have a feeling that their students fall behind the curriculum and their learning subjects, and over half of teachers feel that there is a widening learning gap between disadvantaged students and their peers (Sharp et al. 2020). In this study, participants expect from educational leaders to create supportive and inclusive learning environment, and construct feedback for improvement, these qualities work for educational equity. There are no one-fit-all educational decisions during COVID-19 pandemic; rather, as suggested by Sahlberg and Hasak (2017), educational leaders should turn towards "small data" to help them determine the best educational actions, school priorities and curriculum goals for their learners. Roache, Rowe-Holder and Muschette (2020) argue that skilled leadership is imperative to have the vision to create policies which are aligned to the mission and vision of the institution. Leadership must be strategic in making these decisions which will have growing benefits for the institution. Also, there is a need for a synthesizing model which will integrate the local priorities, school vision, online distance instruction. This necessity is referred in the study of Fullan et al. (2020). They suggest a new hybrid model during COVID-19 pandemic which integrates the best of remote-learning and school situated learning. This hybrid model "embraces digital to amplify, accelerate and connect learners and learning, while intentionally focusing on global competencies as well as academic standards".

c) Calmness and Compassion - The findings of this study indicate that students during COVID-19 pandemic expect from the educational leaders a very important feature: keeping calmness and compassion. Roy et al. (2020) express that as long as higher education institutions remain student-centered, students' health and well-being are key areas of support that should be addressed. Unfortunately, some university students are facing emotional distress as a direct result of the pandemic (Roy et al. 2020). For instance, to mitigate the stress of staying at home for extended periods, some universities in China have provided counselling services to students (Wang, Cheng, Yue \& McAleer, 2020). This study indicates that students expect from educational leaders to keep their calmness when there are risky situations which provoke emotional reactions in learners. Calmness dimension of educational leadership consists of leading under pressure, emphasizing optimism, caring for learners and inspiring for learning. The data suggests that educational leaders for new normal should avoid emotionally loaded explanations during pandemic and must set forth rational objectives by keeping calm and instilling hope.

Making reasonable demands on colleagues and having patience for others and self are imperative for educational leaders (Harris, 2020). One of the most prominent features of educational leaders for new normal is to promote an atmosphere which participants feel themselves hopeful and cared. Students believe that educational leadership grows out of considerate behaviour. During COVID-19 pandemic, what university students need is responsive leadership, not such a model leadership devoid of feelings. Participants report that the best educational leaders are those who show compassion by caring for learners and inspiring for learning. An educational leadership which focuses on compassion as a strategy to achieve institutional mission and curriculum goals will be a productive leading style. On the contrary, an educational leadership which neglects compassion will fail its intentional meaning. Enhancing educational practices and transparency features of educational leadership are interconnected with calmness and compassion.

When leadership studies are reviewed, it is evident that staying calm, being positive, optimism and responsibility are often cited as crucial in terms of leadership. In study of Vogel (2012), it is reported that responsibility, accountability, compassion, calmness are identified as important and guiding values for practicing educational leadership. Evans (2020) 
emphasizes that throughout pandemic process, leading faculty out of crisis requires a crucial leadership feature: leading with empathy. Caring for others' feelings and compassion for their real-life challenges really matter in times of pandemic. Evans encourages faculty to help university students cope with challenges such as stress, anxiety, social isolation, death of a loved one with strategies such as being flexible and understanding, showing compassion, and staying connected. Forester and McKibbon (2020) highlight that leadership matters in the time of COVID-19 not formally but interactively and socially. They advise leaders to show people how to go on all the time, how to treat each other and how to think of future and new normal. It is expected from leadership to show how to act by exhibiting and modelling compassion, and more or less empathy. Likewise, Tran, Hardie and Cunningham (2020) focus on leading with empathy and humanity when managing dilemmas and challenges caused by COVID-19 pandemic. They note that all education leaders are forced into taking immediate actions and respond to the uncertainties. An educational leader participating in their study holds faculty meeting each week, supports teachers to be empathetic with the problems of their students, and accept empathy as a cornerstone of his leadership style by expressing that school culture is centered around compassion more than ever.

Applying compassion to learning and teaching, this uncertain pandemic times should encourage educational leaders to focus their strategies including compassionate practices in order to reduce collective stress. Educational leaders should give a message that they are responsive to others' thoughts, care for their needs and welfare, and attempt to inspire for new normal, not just sympathetically acknowledge their stress. The data also indicates that educational leaders should show compassion to themselves (considering new pressures on them) in order to keep their compassion for others. In leadership study of Lawton-Misra and Pretorius (2021), it comes out that pandemic has highlighted the need for person- and peopleoriented leadership with a focus on among others, caring, empathy and compassion. What becomes clear during the reflections is that empathy, vulnerability, self-awareness and agility are some of the qualities needed during this crisis. Leaders are expected to not only fully understand the meaning of empathy and compassion, but to know how to sincerely demonstrate these qualities to staff and students alike. While these qualities should be expected of educational leaders at all times, the pandemic brought them into sharper focus (Lawton-Misra \& Pretorius, 2021).

d) Transparency - The findings of this study indicate that students during COVID-19 pandemic expect transparency from educational leaders. As seen in findings, transparency with its components of trust, organizational culture and open dialogue is a key aspect of educational leadership. The data suggests that educational leaders for new normal be honestly transparent with their learners/followers. University students in this study feel the need to trust their educational leaders; however, this can be supplied only when there is an open dialogue between educational leader and online community. They also expect from educational leaders to create organizational culture which means that announcements are not made superficially and by non-authorized people but made officially by the educational leaders within organizations. Most of the students put high emphasis on trust and organizational culture.

Transparency requires sharing with empathy and optimism which is connected to calmness and compassion aspect of educational leadership. Students expect to trust their educational leaders, to perform an open dialogue, to be hopeful and have a sense of control. As emphasized by Marshall et al. (2020), this pandemic reinforces the importance of frequent and transparent communication; it is key to providing reassurance and a degree of comfort to 
stakeholders during periods of ambiguity and heightened anxiety. They propose that during turbulent times, communication must be clear and timely. Despite the complexity and uncertainty associated with COVID-19, leaders should communicate clearly during challenging situations. With reference to the COVID-19 pandemic, at a higher education institution in Barbados, leaders made a concerted effort to communicate with stakeholders frequently. This approach cultivates respect and support for leaders and fosters a sense of comfort among stakeholders that every effort is being made to manage the situation effectively (Marshall et al., 2020). Chisholm-Burns, Brandon and Spivey (2021) conduct a study which aims to describe the leadership lessons learned by an academic faculty during the COVID-19 pandemic from the perspective of administrators, faculty, and students. Five main themes emerge across all three focus groups, which include open and ongoing communication, staying connected, turning crisis into opportunity, being adaptable/flexible, and finding ways to stay productive. It is concluded that core leadership practices in emergent situations like the COVID-19 pandemic include adaptability to the changing environment, communicating accurately and with appropriate frequency, which illustrate the need for flexibility during times of crisis.

Transparency as part of educational leadership is also emphasized in the study of Vogel (2012) who examines the guiding values which shape the ethical framework of educational leaders who follow doctoral degree in Educational Leadership. The role of transparency is clearly indicated as important, and it helps people to trust as they believe there is nothing to hide. These obviously require more effort and transparency places new pressures on educational leaders. Transparency aspect of leadership points to the need for educational leaders to be trusted, rather than hiding information. Trocchia and Andrus (2003) list integrity, honesty and fairness as the top characteristics of leadership, which all support transparency. Joseph and Winston (2005) search for a relationship between leadership and trust, and finds out a positively significant relationship between leadership and leader trust.

Additionally, Bryman (2007) associates effective leadership behaviour with providing clear guidance. Providing clear guidance is closely related to organizational culture and open dialogue. In the study of Lesinger et al. (2016), it is identified a significant relationship between educational leadership, organizational culture and trust in schools. Educational leadership is significantly related to school culture and organizational trust. Leaders with a higher organizational culture have the highest level of educational leadership. Cogaltay and Karadag (2016) conduct meta-analysis in order to test the effect of educational leadership on some organizational variables. The findings of meta-analysis indicate that educational leadership has large positive effects on organizational commitment, organizational trust and organizational culture. This supports trust and embraces open dialogue between leaders and the community.

When it comes to studies during COVID-19 crisis, trust still appears as important aspect in educational leadership. Dolan, Raich, Garti and Landau (2020) view COVID-19 crisis as an opportunity for introspection, and accept trust as the value of values, specifically during pandemic. They explain the reason as trust takes time to build, and very difficult to restore. Also, for new normal, learners will lead learning in global virtual "schools" and teachers are expected to be trusted educational leaders. Fernandez and Shaw (2020) investigate the academic leadership in times of COVID-19 crisis, and they claim that leading an educational institution in a crisis is stressful and leader's role is even greater in times of change. They list connecting with people as individuals and establishing mutual trust as the best leadership practices and they also put emphasis on involvement and collaboration. In their study, it is 
advised that leaders with emotional intelligence should place others' interests over their own. Also, they advise leaders to communicate clearly and frequently to all stakeholders through a variety of communication channels.

Despite of difficulty of measuring transparency, most educational institutions do not regard transparency as a strategy which will improve their performance; however, transparency is an effective aspect of educational leadership for new normal on which it is worth making investment. For educational leaders, it is advised to improve their relationship with the community by creating trust, maintaining organizational culture and following an open dialogue. Pekkola et al. (2021) claim that the COVID-19 pandemic has been managed effectively at Finnish universities. In their study on academic leadership during pandemic in higher education, it interestingly comes out that deans' responses are slightly more negative than those of rectors. They express that higher education is dislocated, disconnected, disengaged, dissipated, distant and dysfunctional. According to the academic leaders, the key difficulty during COVID-19 crisis is that the instructions from the authorities are ambiguous, leaving much room for interpretation. The actors affected by coronavirus pandemic hope for more open conversations and negotiations, and for the issues to be dealt with through more cooperation at a higher education institution.

e) Analytical and strategical thinking- it is considered as one of the characteristics of educational leadership for new normal. The analysis indicates that a good educational leader for new normal makes data-driven decisions, plans the risks, creates strategies for long term and leverages the capacity of community. These are mentioned as best practices of analytical and strategical thinking, which inherently affect the overall performance of educational leaders during COVID-19 pandemic. As emphasized by Gurr and Drysdale (2020) in their study of leadership for challenging times, it is strongly stressed that leadership for new normal is about setting direction and often it requires the courage to take strategic risks. It is hard to move forward without taking risks or challenging the status quo, and yet there needs to be a balance between seeking and avoiding risks during pandemic. In this study, it is obvious that educational leadership for new normal should be capable of understanding what the data says and base their decisions on the data analysis to identify what is needed for school improvement and academic achievement. Their decisions should not save the day, rather focus on a strategy for a long period of time as the future is uncertain due to pandemic. It is interconnected with enhancing educational practices. Also, it appears that a good educational leader should know how to leverage the strengths of members within community. This leveraging the capacity of community is fundamental to educational leadership as each member of the community has his/her contribution towards school development and academic achievement. Educational leaders should discover and develop the strengths of members in the group, and then maximize the overall benefit from the group to achieve better outcomes.

Rice University makes use of strategical thinking to ensure consistency, for instance they make use of communication effectively as communication in a crisis is a delicate balancing act; too much and the message is tuned out, too little may prompt concern and anxiety (Field, 2020). Ariratana, Sirisookslip and Ngang (2015) come up with guidelines for developing educational leadership and it appears that strategic planning is a key part of leadership. According to them, strategic planning includes collection of resource to provide together with community. Information technology should also be utilized for making decisions for an effective leadership. They make survey research to assess leadership skills among educational leaders. However, analytical thinking and problem solving of educational leaders is not high, which come after interpersonal relations, learning, use of information technology, 
professional \& morality and teamwork. Despite its importance, analytical thinking stays very behind. Likewise, in study of Mintrop and Zumpe (2019), it is emphasized that educational leaders are expected to think over the educational solutions, identify the problems, recognize cause-effect relations, act accordingly, implement changes and reflect on this process. Despite this challenging ideal responsibility, educational leaders normally resort to a set of heuristics frequently practiced. Educational leaders instinctively define problems as the absence of solutions, view "change" as filling an empty vessel, comprehend learning as conventionsbased process, and consider "rationality" as something "which works." However, this grounded study indicates that educational leadership is a guiding and influencing process based on analytical and strategical thinking.

Making data-driven decisions as a part of educational leadership during COVID-19 pandemic is a key feature. According to Goldring and Berends (2009), data can serve as a catalyst to propel organizational learning, as it utilizes different types of information from a variety of sources. They point out that data is not only about standardized tests scores, but there can also be different data collected from the students, school programs, student work, formative assessments, portfolios, observations of the quality of teaching. They advise education leaders to employ data to develop a culture of learning for students in the school. In Vogel's (2012) study with educational leaders, a participant educational leader refers to the value of databased decision making by claiming that their decisions must be based on data, not opinion. Its importance shows up for educational leadership for new normal.

Leveraging the capacity of learning community during pandemic is about talent-utilization and talent-development. Leadership in pandemic -distributed by nature- moves attention away from the actions of individual leaders to their interactions with others, resulting in joint activity, joint practice, and capacity building (Harris, 2020). A recent study defined new normal leadership in terms of a focus on people, human resources, mentoring, learning, emotions, development, respect, exchange of ideas, a creative class, trust through sharing, teams, embracing equality, diversity, tolerance, vision, and commitment to the vision, through talent, technology, storytelling, and a dynamic interplay between all stakeholders, employees, customers, investors, shareholders (Fleming \& Millar, 2019). From a similar perspective, Fuller et al. (2020) emphasizes competency-based model and view the Covid-19 pandemic has an opportunity to enhance education with thoughtful engagement and potential improvements. There is felt the need during COVID-19 pandemic for improving the current learning paradigms focusing on competency-based model. This is related to leveraging the capacity of community. Talent-development programs are more important than ever during pandemic. If there is made a critical analysis of this crisis, it might lead to better education models, which really care for developing each individual's talent. Depending on the analysis of this grounded study, it can be suggested that educational leaders can build valuable networks of relationships which nurture both the development of individuals and the whole learning group. This leveraging the capacity of community is mostly neglected by educational leaders; however, it is a great potential available force to improve the quality of learning, achieving school goals and reducing the pressures of educational leaders. This finding is supported by Fernandez and Shaw's (2020) study about academic leadership in times of pandemic. They address to the necessity of distributing leadership responsibilities to a network of teams to improve the quality of the decisions made in crisis resolution. This will also enhance the capacity of teams and reduce the educational leaders' increasing stress. Also, in study of Dumulescu and Muţiu (2021), some attributes emerge as central for educational leadership in higher education, such as unity through decentralization which reveals a community dimension of educational leadership, balancing autonomy with togetherness, 
setting the direction through guidelines, thinking the autonomy of the faculties with the strength of teams. These studies support the finding that leveraging the capacity of community come into sharper focus during COVID-19 pandemic. When all findings of this study are considered in detail, there are crucial insights for understanding educational leadership for new normal.

\section{Conclusion}

This grounded theory research focuses on the educational leadership for the new normal in higher education during the COVID-19 crisis. Five main aspects of educational leadership are identified as networking, enhancing educational practices, calmness \& compassion, analytical \& strategical thinking and transparency which are supported by educational leadership literature during the pandemic (Chisholm-Burns, Brandon \& Spivey, 2021; Fernandez \& Shaw, 2020; Gurr \& Drysdale, 2020; Harris \& Jones, 2020; Klein, 2012; Lawton-Misra \& Pretorius, 2021; Maas et al., 2020; Marshall, Roache \& Moody-Marshall, 2020; Pekkola et al., 2020; Samoilovich, 2020; Talu \& Nazarov, 2020). Certain leadership practices such as networking, calmness and compassion are more connected to educational leadership for the new normal. This study indicates that university students need to stay connected and informed within online communities and they request more transparency in which leaders openly share both good and unfavorable developments and give feedback which in turn hopefully strengthens trust and organizational culture between followers and leader. Most of the participants expect from educational leaders to create supportive and inclusive learning environment, construct feedback for improvement, create a vision of academic success and provide resources for learning. Enhancing educational practices is a potentially significant concept within a higher education institution context and educational leadership is connected to achieving institutional goals and academic development. University students suggest that it needs to be a part of educational leadership to accomplish the goals of department, curriculum and to contribute to the visions of school organization. Also, another key feature of educational leadership is calmness and compassion during pandemic, in which students profoundly need educational leaders to lead under pressure, emphasize optimism, care for learners, and inspire for learning. Analytical and strategical thinking is still important for educational leadership for the new normal as the educational leadership generally requires making data-driven decisions, risk-planning of the instructional and organizational process. Educational leadership is changing during COVID-19 crisis and leading the new normal requires considerable attention. The notion of educational leadership which undermines community, calmness and transparency is likely to fail in terms of faculty development and academic performance as it will have very insignificant effects on students in higher education. Consequences of COVID-19 pandemic and new expectations from educational leaders mitigate the need for different leadership behaviours.

\section{References}

Akbari, T. T., \& Pratomo, R. R. (2021). The new normal leadership: How technology alter communication style in contemporary organization. Jurnal Komunikasi Ikatan Sarjana Komunikasi Indonesia, 6(1), 1-12.

Amey, M. (2006). Leadership in higher education. Change: The Magazine of Higher Learning, $38(6), 55-58$.

Antonakis, J., Day, V. D., \& Schyns, B. (2012). Leadership and individual differences: At the cusp of a renaissance. The Leadership Quarterly, 23(4), 643-650. 
Antonopoulou, H., Halkiopoulos, C., Barlou, O., \& Beligiannis, G. N. (2021). Transformational leadership and digital skills in higher education institutes: during the COVID-19 pandemic. Emerging science journal, 5(1), 1-15.

Ariratana, W., Sirisookslip, S., \& Ngang, T. K. (2015). Development of leadership soft skills among educational administrators. Procedia-Social and Behavioral Sciences, 186, 331336.

Balwant, T. P. (2016). Transformational instructor-leadership in higher education teaching: A meta-analytic review and research agenda. Journal of Leadership Studies, 9(4), 20-42.

Bass, M. B. (1985). Leadership and performance beyond expectations. New York: The Free Press.

Boin, A., Kuipers, S., \& Overdijk, W. (2013). Leadership in times of crisis: A framework for assessment. Int Rev Public Adm, 18, 79-91.

Bolden, R. (2020). Leadership, complexity and change: Learning from the Covid-19 pandemic. https://blogs.uwe.ac.uk/leadership-and-change/

Bolden, R., Petrov, G., \& Gosling, J. (2009). Distributed leadership in higher education: Rhetoric and reality. Educational Management Administration \& Leadership, 37 (2), 257-277.

Brooks, S. J., \& Normore, H. A. (2010). Educational leadership and globalization: Literacy for a glocal perspective. Educational Policy, 24(1), 52-82.

Bryant, A. (2017). Grounded theory and grounded theorizing: Pragmatism in research practice. New York: Oxford University Press.

Bryman, A. (2007). Effective leadership in higher education: A literature review. Studies in Higher Education, 32(6), 693-710.

Bryman, A., \& Bell, E. (2007). Business research methods. New York: Oxford University Press.

Bush, T., \& Glover, D. (2014). School leadership models: What do we know?, School Leadership and Management, 34(5), 553-571.

Chisholm-Burns, M. A., Brandon, H. H., \& Spivey, C. A. (2021). Leadership lessons from administrators, faculty, and students during the COVID-19 pandemic. Currents in Pharmacy Teaching and Learning. doi: 10.1016/j.cpt1.2021.07.001

Cogaltay, N., \& Karadag, E. (2016). The effect of educational leadership on organizational variables: A meta-Analysis study in the sample of Turkey. Educational Sciences: Theory and Practice, 16(2), 603-646.

de Moura, G. (2020). Cybersecurity leadership principles: lessons learnt during the covid-19 pandemic to prepare for the new normal. World Economic Forum, Não Convencional, Homeland Security Digital Library.

Dolan, L. S., Raich, M., Garti, A., \& Landau, A. (2020). The COVID-19 crisis as an opportunity for introspection: A multi-level reflection on values, needs, trust and leadership in the future. The European Business Review. 1-17

Dugan, P. John, and Komives, R. S. (2007). Developing Leadership Capacity in College Students: Findings from a National Study. A report from Multi-Institutional Study of Leadership: College Park, MD: National Clearinghouse for Leadership Programs.

Dugan, P. J., \& Komives, R. S. (2010). Influences on college students' capacities for socially responsible leadership. Journal of College Student Development, 51(5), 525-549.

Dumulescu, D., \& Muţiu, A. I. (2021). Academic leadership in the time of COVID-19Experiences and perspectives. Frontiers in Psychology, 12, 1272.

Evans, N. (2020). Leading with empathy: Supporting faculty through COVID-19 and beyond. The Department Chair, 31(1), 25-26.

Fernandez, A. A., \& Shaw, G. P. (2020). Academic leadership in a time of crisis: The coronavirus and COVID-19. Journal of Leadership Studies, 14(1), 39-45.

Field, K. (2020, March 26). 5 lessons from campuses that closed after natural disasters. The Chronicle of Higher Education. https://www.chronicle.com/article/5-Lessons-FromCampuses-That/248346 
Fleming, K., \& Millar, C. (2019). Leadership capacity in an era of change: the new-normal leader. Journal of Organizational Change Management, 32(3), 310-319. doi: 10.1108/JOCM-052019-492

Forester, J., \& McKibbon, G. (2020). Beyond blame: leadership, collaboration and compassion in the time of COVID-19. Socio-Ecological Practice Research, 1-12.

Francisco, C. D., \& Nuqui, A. V. (2020). Emergence of a situational leadership during COVID-19 pandemic called new normal leadership. Online Submission, 4(10), 15-19.

Fullan, M., Quinn, J., Drummy, M., \& Gardner, M. (2020). Education reimagined: The future of learning. A collaborative position paper between New Pedagogies for Deep Learning and Microsoft Education, 1-34.

Fuller, S., Vaporciyan, A., Dearani, A. J., Stulak, M. J., \& Romano, C. J. (2020). COVID-19 disruption in cardiothoracic surgical training: An opportunity to enhance education. The Annals of Thoracic Surgery, 1-11.

Goldring, E., \& Berends, M. (2008). Leading with data: Pathways to improve your school. USA: Corwin Press.

Greenfield, D. W. (1995). Towards a theory of school administration: the centrality of leadership. Educational Administration Quarterly, 31(1), 61-85.

Gunter, H. (2004). Labels and labeling in the field of educational leadership. Discourse - Studies in the Cultural Politics of Education, 25(1), 21-41.

Gurr, D., \& Drysdale, L. (2020). Leadership for challenging times. International Studies in Educational Administration, 48(1), 24-30.

Halverson, R. R. (2007). How leaders use artifacts to structure professional community in schools. Professional learning communities: Divergence, depth and dilemmas, 11(37), 93105.

Harper, R. S. (2020). COVID-19 and the racial equity implications of reopening college and university campuses. American Journal of Education, 127, 1-10.

Harris, A. (2020). COVID-19-School leadership in crisis?. Journal of Professional Capital and Community, Vol. ahead-of-print No. ahead-of-print. doi:10.1108/JPCC-06-2020-0045

Harris, A. \& Jones, M. (2020). COVID 19-school leadership in disruptive times. School Leadership \& Management, 40(4), 243-247

Harris, R. P., Moran, T. R., \& Moran, V. S. (2004). Managing cultural differences: Global leadership strategies for the 21st century. Oxford: Elsevier.

Harvey, S., Royal, M., \& Stout, D. (2003). Instructor's transformational leadership: University student attitudes and ratings. Psychological Reports, 92 (2), 395-402.

Irvine, A., Lupart, J., Loreman, T., \& McGhie-Richmond, D. (2010). Educational leadership to create authentic inclusive schools: The experiences of principals in a Canadian rural school district. Exceptionality Education International, 20(2), 70-88.

Izvercian, M., Potra, S., \& Ivascu, L. (2016). Job satisfaction variables: A grounded theory approach. Procedia-Social and Behavioral Sciences, 221, 86-94.

Jameel, S. A., \& Ahmad, A. (2019, April). Leadership and performance of academic staff in developing countries. Paper presented at the annual meeting of Proceedings of the 33rd International Business Information Management Association Conference, Granada, 61016106.

James, C., Connolly, M., \& Hawkins, M. (2019). Reconceptualising and redefining educational leadership practice. International Journal of Leadership in Education, 1-18. doi: 10.1080/13603124.2019.1591520.

Joseph, E. E., \& Winston, B. (2005). A correlation of servant leadership, leader trust, and organizational trust. Leadership \& Organization Development Journal, 26(1), 6-22.

Juntrasook, A. (2014). You do not have to be the boss to be a leader: Contested meanings of leadership in higher education. Higher Education Research \& Development, 33(1), 19-31.

Klein, J. (2012). The open-door policy: Transparency minimizes conflicts between school principals and staff. International Journal of Educational Management, 26(6), 550-564. 
Knaub, V. A., Henderson, C., \& Fisher, Q. K. (2018). Finding the leaders: An examination of social network analysis and leadership identification in STEM education change. International Journal of STEM Education, 5(1), 26.

Komives, S.R., Owen, J.E., Longerbeam, S., Mainella, F.C., \& Osteen, L. (2005). Developing a leadership identity: A grounded theory. Journal of College Student Development, 46(6), 593-611.

Külekçi, E. (2015). Üniversite ögrrencilerinin sosyal sorumluluk temelli liderlik becerilerinin geliştirilmesine yönelik deneysel bir çalışma [An experimental study about developing undergraduate students' socially responsible leadership skills]. (Doctoral Dissertation). Gaziantep University Educational Sciences Institution, Gaziantep, Turkey.

Lawton-Misra, N., \& Pretorius, T. (2021). Leading with heart: academic leadership during the COVID-19 crisis. South African Journal of Psychology, 51(2), 205-214.

Lesinger, Y. F., Dagli, G., Gazi, A. Z., Yusoff, B. S., \& Altınay, F. (2016). Investigating the relationship between organizational culture, educational leadership and trust in schools. International Journal of Educational Sciences, 15(1-2), 178-185.

Lorenzi, P. (2004). Managing for the common good: Prosocial leadership. Organizational dynamics, 33(3), 282-291.

Maak, T. (2007). Responsible leadership, stakeholder engagement, and the emergence of social capital. Journal of Business Ethics, 74(4), 329-343.

Maas, B., Grogan, K. E., Chirango, Y., Harris, N., Liévano-Latorre, L. F., McGuire, K. L., ... \& Toomey, A. (2020). Academic leaders must support inclusive scientific communities during COVID-19. Nature ecology \& evolution, 4(8), 997-998.

Marshall, J., Roache, D., \& Moody-Marshall, R. (2020). Crisis leadership: A critical examination of educational leadership in higher education in the midst of the COVID-19 pandemic. International Studies in Educational Administration, 48(3), 30-37.

Middlehurst, R., Goreham, H., \& Woodfield, S. (2009). Why research leadership in higher education?: Exploring contributions from the UK's leadership foundation for higher education. Leadership, 5(3), 311-329.

Mintrop, R., \& Zumpe, E. (2019). Solving real-life problems of practice and education leaders' school improvement mind-set. American Journal of Education, 125(3), 295-344.

Murashkin, M., \& Tyrväinen, J. (2020). Adapting to the new normal: A qualitative study of digital leadership in crisis (Unpublished Master Thesis). Department of Business Administration, Umeå School of Business, Economics and Statistics.

Murphy, P. M. (2020). COVID-19 and emergency elearning: Consequences of the securitization of higher education for post-pandemic pedagogy. Contemporary Security Policy, 41(3), 114.

Pekkola, E., Siekkinen, T., Kujala, E. N., Kanniainen, J. P., \& Laihonen, H. (2021). An assessment of COVID-19's impact on Finnish University Leadership. Knowledge Management Research \& Practice, 1-7.

Pollock, K. (2020). School leaders' work during the COVID-19 pandemic: A two-pronged approach. International Studies in Educational Administration, 48(3), 38-44.

Roache, D., Rowe-Holder, D., \& Muschette, R. (2020). Transitioning to online distance learning in the COVID-19 era: A call for skilled leadership in higher education institutions (HEIs). Proceedings CCEAM, 103.

Roy, D., Tripathy, S., Kar, S. K., Sharma, N., Verma, S. K., \& Kaushal, V. (2020). Study of knowledge, attitude, anxiety \& perceived mental healthcare need in Indian population during COVID-19 pandemic. Asian Journal of Psychiatry, 51, 1-8.

Sahlberg, P., \& Hasak, J. (2017). Small data for big change. Education, 98(1), 7.

Samoilovich, D. (2020). Leadership in the time of COVID-19: reflections of Latin American higher education leaders. International Higher Education, 102, 32-34. 
Sellami, A. L., Sawalhi, R., Romanowski, H. M., \& Amatullah, T. (2019). Definitions of educational leadership-arab educators' perspectives. International Journal of Leadership in Education, 1-20. doi: 10.1080/13603124.2019.1690701.

Sharp, C., Nelson, J., Lucas, M., Julius, J., McCrone, T., \& Sims, D. (2020). Schools' Responses to Covid-19: The Challenges Facing Schools and Pupils in September 2020. Slough: National Foundation for Educational Research.

Spendlove, M. (2007). Competencies for effective leadership in higher education. International Journal of Educational Management, 21(5), 407-417.

Supovitz, A. J., \& Christman, J. B. (2005). Small learning communities that actually learn: Lessons for school leaders. Phi Delta Kappan, 86(9), 649-651.

Strack, R., Kugel, J., Dyrchs, S., \& Tauber, M. (2020). Leadership in the new now. Boston Consulting Group.

Strauss, A., \& Corbin, J. (1990). Basics of qualitative research: Grounded theory procedures and techniques. CA: Thousand Oaks, Sage Publications.

Talu, S., \& Nazarov, A. D. (2020). Challenges and competencies of leadership in Covid-19 Pandemic. Proceedings of the Research Technologies of Pandemic Coronavirus Impact (RTCOV 2020), Advances in Social Science, Education and Humanities Research, 486, 518-524.

Tran, H., Hardie, S., \& Cunningham, M. W. K. (2020). Leading with empathy and humanity: Why talent-centred education leadership is especially critical amidst the pandemic crisis. International Studies in Educational Administration, 48(1), 39-45.

Trocchia, J. P., \& Andrus, M. D. (2003). Perceived characteristics and abilities of an effective marketing department head. Journal of Marketing Education, 25(1), 5-15.

Unesco. (2020). COVID-19 and Higher Education: Today and Tomorrow Report. April 9.

Varela, D. G., \& Fedynich, L. (2020). Leading schools from a social distance: Surveying South Texas school district leadership during the COVID-19 pandemic. National Forum of Educational Administration and Supervision Journal, 38(4), 1-10

Vogel, L. R. (2012). Leading with hearts and minds: Ethical orientations of educational leadership doctoral students. Values and Ethics in Educational Administration, 10(1), 1-12.

Wang, C., Cheng, Z., Yue, X., \& McAleer, M. (2020). Risk management of COVID-19 by universities in China. 13(2), 36.

Wasserman, S., \& Faust, K. (1994). Social network analysis: Methods and applications. Cambridge: Cambridge University Press.

Wing, N. S. (2013). Equipping the aspiring principal for the principalship in Hong Kong. Educational Management Administration and Leadership, 41(3), 272-288.

Yokuş, G. (2018). Analysis of online professional learning networks' effect on pre-service teachers' researcherly dispositions, socially responsible leaderships and social networks based learning: Digital teacher community. (Unpublished Doctoral Dissertation). Mersin University Educational Sciences Institution, Mersin, Turkey. 